MATEC Web of Conferences 22,03010 (2015)

DOI: $10.1051 /$ matec conf/ 20152203010

(C) Owned by the authors, published by EDP Sciences, 2015

\title{
Injection Mould Design and Analysis of the Telephone Base Based on Pro/E
}

\author{
Wen Kong*, Tiezhu Zhang \& Hong Zhao \\ School of Mechanical and Electrical Engineering, Qingdao University, Qingdao, Shandong, China
}

\begin{abstract}
The 3D models of a telephone base and its whole mould are established by Pro/E, and it simulated the process of opening the mould. The parametric design process of the injection mould is elaborated in detail, and then the general steps of designing injection mould are presented. The main basis of injection machine is listed and to check the main parameters. In the structure of design process, the design principles of parts followed are cited, and carried on the concrete analysis with this topic. Finally, the key point is focused on the analysis and design of thermal control system, and it illustrated the importance of thermal control system for product molding. The heat into the mould is calculated in detail, and the main parameters of cooling process such as cooling waterway diameter, cooling channel length are confirmed at last.
\end{abstract}

Keywords: injection mould; parametic design mould; joint; process parameters; Pro/E

\section{INTRODUCTION}

With the development of software technology, the invention of the 3D design makes the mould design implement the visualization and improve the assembly. The mold development from 2D to 3D design realizes the breakthrough of mold design technology:

(1)3D mould design can make the unprocessed mould ontology reappear spatially and intuitively. The design data can be directly used for processing, realized the integration of CAD and CAM, and processed with less or no drawings;

(2)3D mould design has solved a series of questions that the two-dimensional design is difficult to solve, such as the interference checking and the assembly simulation, CAE and so on.

The telephone base is shell and the surface is smooth, thus, there must have a good processing technology to ensure that the molding part have a certain roughness in the process of mould designing and manufacturing. The injection molding material is ABS. We must have a good conduct to make the thickness of the back cover uniformity, for example, in injection molding process, the uneven wall thickness can cause shrinkage to be not consistent, thus only through effective control of molding temperature can we adjust the shrinkage rate. Through the application of Pro/E to imitate the injection molding process, we can found that it can bring more welding scar and porosity to the surface of the telephone base. Also, the molding process can use reliable precision to locate the mould, but the cost is too high and it's easy to damage the mould ${ }^{[1]}$.

In order to meet the requirement that the surface of the telephone base is smooth, and to improve the efficiency of molding, we used straight gate. In order to reduce the damage for the surface of the plastic piece,

*Corresponding author: 1556186777@.qq.com and simultaneously not affect the surface quality of plastic parts and esthetic result, the gate is at the bottom of the distributary channel in the mould cavity and opened in the mold cavity, fed from plastic bottom longitudinally ${ }^{[2]}$

The process parameters of plastic parts are shown as follows:
(1) Drying conditions: $80-90^{\circ} \mathrm{C} /$ (2 hours)
(2) Mold shrinkage: $0.4-0.7 \%$
(3) Mold temperature: $25-70^{\circ} \mathrm{C}$
(4) Melting temperature: $210-280^{\circ} \mathrm{C}$
(5) Molding temperature: $200-240^{\circ} \mathrm{C}$
(6) Injection speed: medium and high speed
(7) Injection pressure: 500-1000bar

\section{1MOULD AND INJECTION MACHINE}

\subsection{Cavity number}

According to the structure characteristics of the product, the way of the product placed in the molding process is that the rotary axis of plastic products is vertical with the axis of the sprue bushing in the molding, structure of one module and two cavities, and side parting ${ }^{[3]}$.

\subsection{Choice of the injection machine}

\subsubsection{Calculation of plastic volume}

The volume of plastic parts: $V_{1}=92.3 \mathrm{~cm}^{3}$

The volume of gating system: $V_{2}=4.4 \mathrm{~cm}^{3}$

The volume of the plastic parts and gating system: $\mathrm{V}=92.3+4.4=96.7 \mathrm{~cm}^{3}$

\subsubsection{Calculation of the quality of plastic parts:}

Checking the manual for the density: $\rho=1.05 \mathrm{~g} / \mathrm{cm}^{3}$, 


\section{MATEC Web of Conferences}

plastic volume: $\mathrm{V}=96.7 \mathrm{~cm}^{3}$; density of plastics: $\rho=1.05 \mathrm{~g} / \mathrm{cm}^{3}$. So, the weight of the plastic parts: $\mathrm{M}=\mathrm{V} \times \rho=96.7 \mathrm{~cm}^{3} \times 1.05 \mathrm{~g} / \mathrm{cm}^{3}=101.54 \mathrm{~g}$.

\subsubsection{Number of cavity}

According to $n \leq \frac{k m_{p}-m_{1}}{k}$

so

$$
m_{p} \geq \frac{k n+m_{1}}{k}
$$

Where k-utilization coefficient of the maximum injection of injection machine is generally $0.8 ; \mathrm{m}_{\mathrm{p}}$ - is the largest injection quantity of the injection machine, $\mathrm{cm}^{3}$ or $\mathrm{g} ; \mathrm{m}_{1}$ - is the coagulation quantity of the gating system, $\mathrm{cm}^{3}$ or $\mathrm{g}$; $\mathrm{n}$-volume or quality of a single plastic, $\mathrm{cm}^{3}$ or $\mathrm{g}$.

\subsubsection{Volume of a pouring system}

Its initial setting scheme is shown in Figure 1:

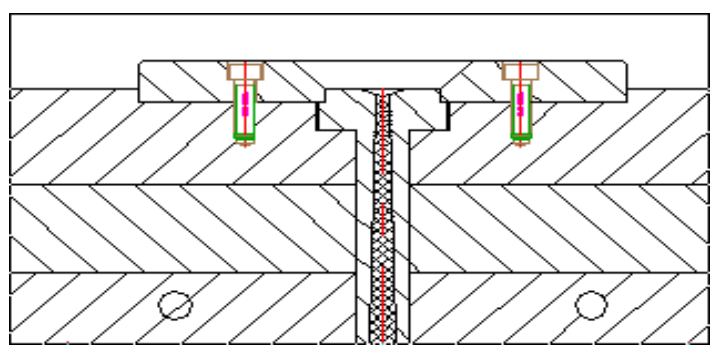

Figure 1. Diagram of gating system

According to the 3D model of the telephone base, Pro/E can be used to query the volume of a pouring system directly: $\mathrm{V}_{2}=4.4 \mathrm{~cm}^{3}$.

\subsubsection{Injection machine}

Choosing the CJ325NCII 3 type of injection machine, its parameters are shown in table 1.

\section{POURING AND COOLING SYSTEM}

\subsection{Gating system}

The mainstream channel(as shown in Figure 2): The flow channel of plastic melts is from the injection machine nozzle to distributary channel in the molding process.

Diameter of nozzle front hole: $\mathrm{d}_{0}=4.0 \mathrm{~mm}$; nozzle front spherical radius: $\mathrm{R}_{0}=10 \mathrm{~mm}$.

According to the relationship of mold sprue and nozzle, we can obtain as follows:

$\mathrm{R}=\mathrm{R}_{0}+(1 \sim 2) \mathrm{mm} \quad \mathrm{d}=\mathrm{R}_{0}+(0.5 \sim 1) \mathrm{mm}$

In this design, the nozzle spherical radius: $\mathrm{R}=11 \mathrm{~mm}$, and the small diameter of mainstream channel: $\mathrm{d}=4.5 \mathrm{~mm}$.
In order to take out the coagulation in the mainstream, the mainstream is conical, and the slope is between $2 \sim 6^{\circ}$, the selection is $2^{\circ}$ here. After the conversion, the big end diameter of mainstream is 7.68 $\mathrm{mm}$.

Table 1. Parameters of injection machine Type of injection machine CJ325NCII 3 Parts of molding

Injection weight $\quad 1020 \quad \mathrm{~g}$

Injection capacity $\quad 1149 \quad \mathrm{~cm}^{3}$

Injection pressure $\quad 153 \quad \mathrm{mpa}$

Injection stroke $\quad 260 \quad \mathrm{~mm}$

Spout radius $\quad 10 \quad \mathrm{~mm}$

Nozzle hole diameter $\quad 4 \quad \mathrm{~mm}$

Positioning ring diameter $\quad 150 \quad \mathrm{~mm}$

Parts of mode locking

Clamping force $\quad 3250 \quad \mathrm{KN}$

Clamping Stroke $\quad 650 \quad \mathrm{~mm}$

Mould-opening stroke $\quad 1350 \quad \mathrm{~mm}$

Platen Size(HXV) $\quad 1020 \times 933 \quad \mathrm{~mm}$

Guide pillar spacing $(\mathrm{HXV}) \quad 650 \times 590 \quad \mathrm{~mm}$

Minimum thickness of molar $\quad 250 \quad \mathrm{~mm}$

largest thickness of molar $\quad 700 \quad \mathrm{~mm}$

Ejecting force $\quad 73 \quad \mathrm{KN}$

Ejection stroke $\quad 150 \quad \mathrm{~mm}$

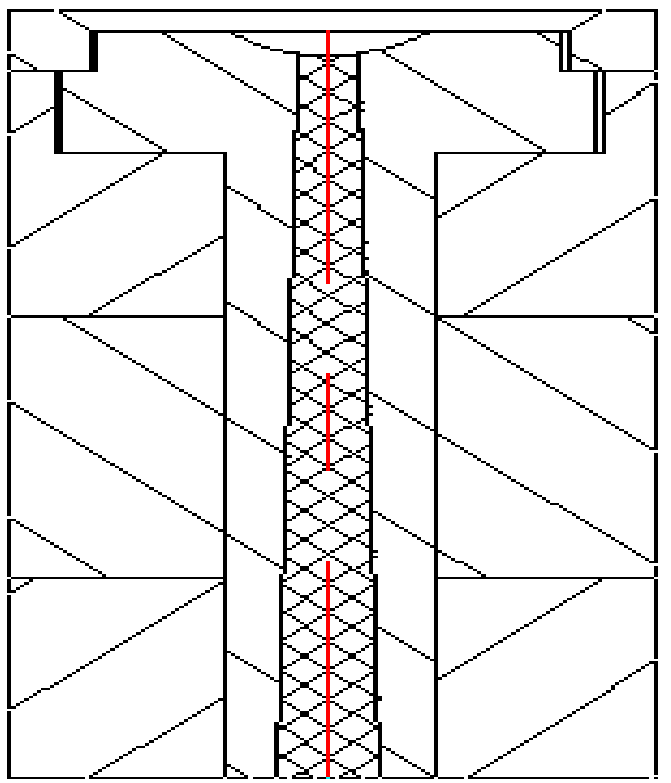

Figure 2. Diagram of the mainstream

3.1.1 Design principles of parting surface

(1)Form of parting surface

There is only a vertical parting surface in the mould. 
(2)Design principles of parting surface

Many factors such as the position plastic part in the mould, the design of gating system, molding process precision, shape, and introducing methods of plastic parts will affect the selection of parting surface. Through comprehensive analysis, the parting surface of the telephone base is shown in Figure 3:

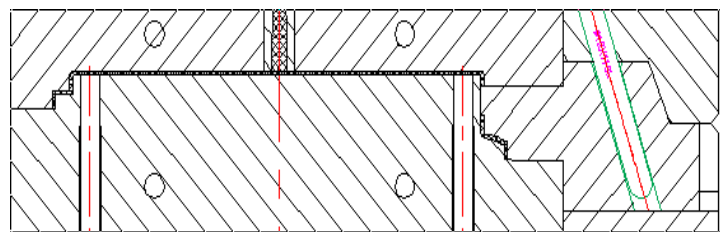

Figure 3. Diagram of parting surface

\subsection{Cooling system}

The average mold temperature for working is $60^{\circ} \mathrm{C}$. Using room temperature water of $20^{\circ} \mathrm{C}$ as the mold cooling medium, the outlet temperature is $30^{\circ} \mathrm{C}$.

\subsubsection{Cooling waterway diameter}

Looking at the Table 3-26, the unit flow of ABS is $35 \times 104 \mathrm{j} / \mathrm{KG}$. On the basis of plastic volume, the diameter of cooling water pipe is $10 \mathrm{~mm}$. The cooling water channel is shown in Figure 4.

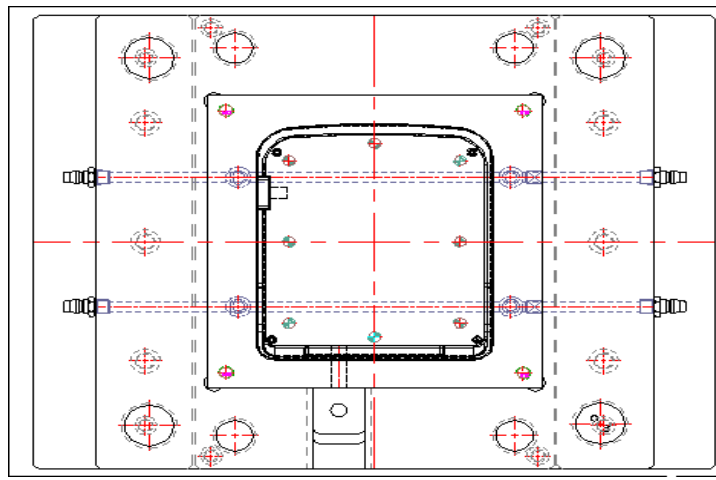

Figure 4. Diagram of cooling waterway system

\section{MAIN STRUCTURE SIZE}

\subsection{Calculation of cavity and core size}

Shrinkage rate of ABS: $0.3 \% \sim 0.8 \%$
Average shrinkage:
$Q_{\text {average }}$
$=(0.3 \% \sim$

Chooses this design: $0.5 \%$

Cavity diameter: $\mathrm{D}_{\text {mould }}=\left(\mathrm{D}+\mathrm{DQ}_{\text {average }}-\frac{3}{4} \Delta\right)^{+\delta}=$

$796.8 \mathrm{~mm}$

Cavity depth: $\quad \mathrm{H}_{\text {mould }}=\left(\mathrm{H}+\mathrm{HQ}_{\text {average }}-\frac{2}{3} \Delta\right)^{+\delta}$

$=33.94 \mathrm{~mm}$

Core diameter: $\mathrm{d}_{\text {mould }}=\left(\mathrm{d}+\mathrm{dQ}_{\text {average }}+\frac{3}{4} \Delta\right)^{-\delta}=$

$761.97 \mathrm{~mm}$

Core depth: $\mathrm{h}_{\text {mould }}=\left(\mathrm{h}+\mathrm{hQ}_{\text {average }}+\frac{2}{3} \Delta\right)^{-\delta}$

$=32.43 \mathrm{~mm}$

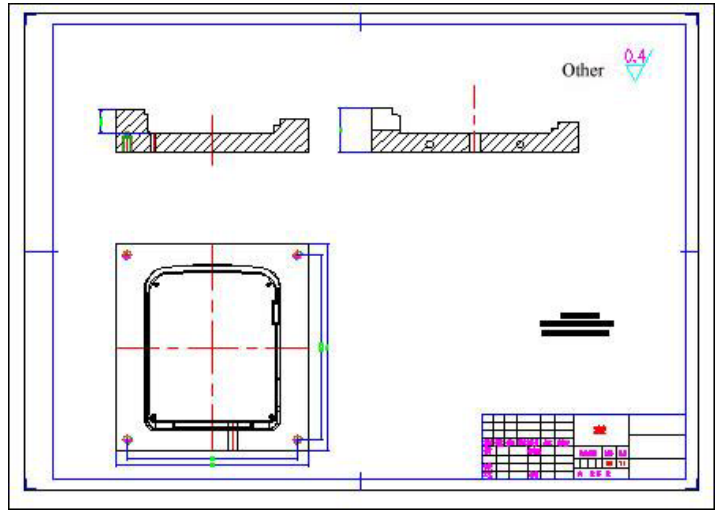

Figure 4. Cavity

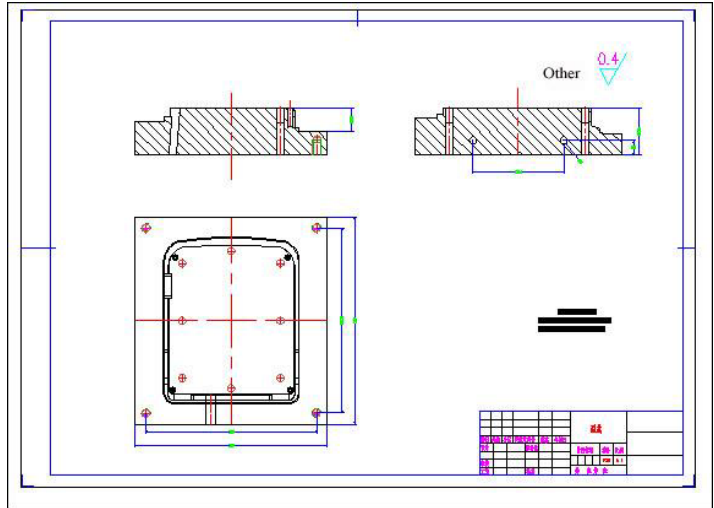

Figure 5. Core 


\section{MATEC Web of Conferences}

Where $\mathrm{D}_{\text {mould }}$ is the cavity radial size ( $\left.\mathrm{mm}\right)$; $\mathrm{D}$ is the basic outline dimensions $(\mathrm{mm})$; $\mathrm{Q}_{\text {average }}$ is the average shrinkage; $\Delta$ is the tolerance of plastic parts; $\delta$ is the manufacturing tolerance of forming parts, usually, $1 / 4-1 / 6 \Delta ; d$ is the basic size in plastic parts $(\mathrm{mm})$; $\mathrm{d}_{\text {mould }}$ is the core radial size $(\mathrm{mm}) ; \mathrm{H}_{\text {mould }}$ is the depth of the cavity $(\mathrm{mm}) ; \mathrm{H}$ is the height of plastic pieces $(\mathrm{mm})$; $\mathrm{d}_{\text {mould }}$ is the core height $(\mathrm{mm}) ; \mathrm{H}$ is the basic deep size of plastic hole $(\mathrm{mm})$. Figure 4 is the three-view drawing of the cavity, and Figure 5 is the three-view drawing of the core.

\subsection{Side pumping mechanism}

\subsubsection{Calculation of core-pulling distance}

The computation formula of the core pulling distance is shown as follows:

$$
S=S_{1}+(2 \sim 3)=13.77+2.23=16(\mathrm{~mm})
$$

Where $\mathrm{S}$ is the core-pulling distance $(\mathrm{mm}) ; \mathrm{S}_{1-}$ is the minimal size of plastic pieces $(\mathrm{mm})$.

\subsubsection{Oblique guide pillar parting core-pulling}

The most widely-used parting core-pulling mechanism is the oblique guide pillar parting core-pulling. It completes lateral core pulling in the process of parting with the mould opening force, its simple structure, easy fabrication, and the reliable parting action. Its structure is shown in Figure 6, the disc clamping slide block is installed in the T guide chute, so it can glide smoothly in the direction of the pull. The inclined guide pillar installed obliquely with the moving direction of opening mould, the inclined guide pillar fitted with slide block corresponding hole, and the inclined guide pillar moving relatively against the slide block when opening mould, which generates the lateral force component on the slider and forces the slider to finish the core-pulling motions ${ }^{[4]}$

(l)

Figure 6. Core-pulling mechanism schematic diagram of the inclined guide pillar parting

The angle of the inclined guide pillar is $20^{\circ}$. The size of the inclined guide pillar is shown in Figure 6. Material is made of high quality steel of T8A, and the quenched hardness is HRC55 60 .

When the direction of the slide block out mould is vertical with the opening direction, the computation formula of the length of the inclined guide pillar is shown as follows:

$L=\left(\frac{D+d}{2}\right) \operatorname{tg} \alpha+\frac{h}{\cos \alpha}+\frac{S}{\sin \alpha}+(10 \sim 15)=116(\mathrm{~mm})$

Where $\mathrm{L}$ is the total length of oblique guide pillar $(\mathrm{mm})$; D is the diameter of the big end $(\mathrm{mm})$; $\mathrm{S}$ is the distance of pulling $(\mathrm{mm}) ; \mathrm{d}$ is the diameter of the slide guide section $(\mathrm{mm}) ; \mathrm{h}$ is the thickness of the fixed template $(\mathrm{mm}) ; \alpha$ is the inclination of the inclined guide pillar $\left(20^{\circ}\right)$

\subsection{Selection of the die-set}

There are two national standards of injection molding die-set: GB/T12556-1990 and GB/T12555-1990 $0^{[5]}$.Due to the nowadays rapid development of plastic mold, the essential standard is formed in parts of the country. The design is shown in Figure 7 and the dragon standard mould frame is adopted. Its type is FCI4545A80B100.

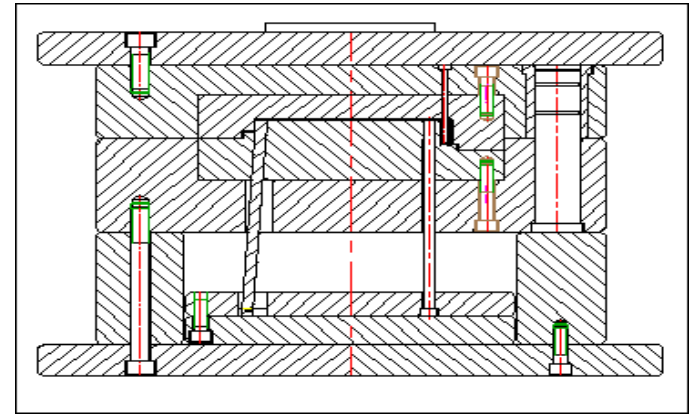

Figure 7. Diagram of mould frame

\section{STEERING MECHANISM AND EXHAUST SLOT}

\subsection{Ejecting mechanism}

The cross section of pushbeam is circular; the pushbeam rod is flexible and reliable and he pushbeam is easily changed after damage, too. Combined with the structure characteristics of telephone base, the integral cavity is used for the mold, and the precision of this kind of structure is higher in the process of the injection molding, and it's easier to get in this process. In order to prevent the push rod from breaking off for the bending force or the lateral pressure in the operation, the combined putter is used in the launch mechanism. Because the product is smaller on the side, it's easy to replace after broken. Here, the fixed plates are fixed at the top of the putter ${ }^{[6]}$.

The location of the push rod should be where the stripping resistance is the biggest. If the stripping resistances of all the plastic parts are the same, all parts 
ICETA 2015

of the plastic will be arranged uniformly, so that it can make sure the requirements of the push rod. Based on the stiffness and strength of the push rod itself, and after putting into the mold, the face also should be with the cavity bottom level or higher cavity $0.05-0.1$ $\mathrm{mm}^{[7]}$.

5.1.1 Calculation of the force of push rod

For the general model and the shell shape parts, the ejection force is calculated according to the following formula ${ }^{[8]}$ :

$$
Q=\operatorname{Lhp}(f \cos \alpha-\sin \alpha)
$$

Where $\mathrm{L}$ is the perimeter of the cross section of the parts of core or punch tightly wrapped $(\mathrm{cm}) ; \mathrm{h}$ is the depth of the folded tightly parts $(\mathrm{cm}) ; \mathrm{p}$ is the positive pressure on the unit area by the shrinkage of the plastic parts, which is between $7.8 \sim 11.8 \mathrm{MPa}$; $\mathrm{f}$ is the coefficient of friction which is between $0.1 \sim 1.2$; $\alpha$ is the coefficient of friction.

$\mathrm{L}=761.97 \mathrm{~mm}$

$\mathrm{h}=32.43 \mathrm{~mm}$

$\mathrm{Q}=761.97 \mathrm{~mm} \times 32.43 \mathrm{~mm} \times 10 \mathrm{MPA} \quad[0.1 \times \cos (0.5)$ $\sin (0.5)]=2471.1(\mathrm{~N})$

\subsubsection{Design of the push rod}

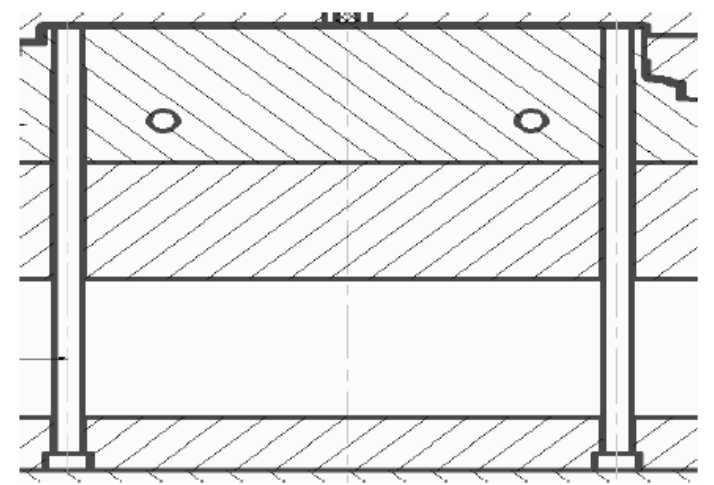

Figure 8. Launch institution

1) The strength of the push rod is calculated according to the following formula:

$\mathrm{D}=\left(\frac{64 \times \phi^{2} \times 1^{2}}{n \times \pi^{3} \times E} \times Q\right)^{\frac{1}{4}}$

Where $\mathrm{d}$ is the diameter of the circular push $\operatorname{rod}(\mathrm{cm}) ; \phi$ is the length factor of the $\mathrm{pu}_{\mathrm{s}} \mathrm{h}$ rod which is $0.7 ; 1$ is the length of the push rod $(\mathrm{cm})$; $n$ is the number of the push rod; $\mathrm{E}$ is the elastic modulus of push rod materials $\left(\mathrm{N} / \mathrm{cm}^{2}\right),(\mathrm{E}=2.1 \times 107 \mathrm{~N} / \mathrm{cm} 2)$; $\mathrm{Q}$ is the total ejection force.

$\mathrm{D}=10 \mathrm{~mm}$

2) Check the push rod pressure:

$\sigma=\frac{4 Q}{n \pi \times d^{2}} \leq \sigma_{s}$ $\sigma_{s}=320 \mathrm{~N} / \mathrm{mm}^{2}$

$\sigma \leq \sigma_{s}$

The stress of the push rod is qualified, the rigidity:HRC $50 \sim 65$.

The launch institution is shown in Figure 8.

\section{EXAMINATION}

6.1 Examination of process parameter of injection machine

1) Examination of the clamping force and injection pressure

$F>p\left(n A+A_{1}\right)$

Where $\mathrm{P}$ is the pressure of the cavity injection, $\mathrm{p}=113 \mathrm{MPa} ; \mathrm{A}$ is the projection area of the plastic parts in parting surface $\left(\mathrm{cm}^{2}\right) ; A_{1}$ is the projection area of gating system in parting surface $\left(\mathrm{cm}^{2}\right) ; \mathrm{F}$ is the rated clamping force of injection machine, $F=3250 \mathrm{KN}$. Through calculation, the condition was established.

\subsection{Examination of the distance of mould opening}

The Opening mould distance of the injection machine should be greater than that distance when taking out the plastic parts (including the gating system):

$S \geq H_{1}+H_{2}+(5 \square 10)$

Where $\mathrm{S}$ is the largest distance of the injection machine (mm); $\mathrm{H}_{1}$ is the demoulding distance $(\mathrm{mm}) ; \mathrm{H}_{2}$ is the height pf the plastic parts, including pouring system $(\mathrm{mm})$.

$\mathrm{S}_{\mathrm{k}}=65+106.5=161.5 \mathrm{~mm}$

$\mathrm{S}_{\mathrm{k}} \leq \mathrm{S}=1350 \mathrm{~mm}$

\section{CONCLUSIONS}

The mould design of the telephone base fully demonstrated the advantages of the virtual design. The rated clamping force and the largest distance of the injection machine are accorded with requirement. This paper shows that using Pro/E to finish the model of the injection mould and imitate the process of opening mould can reduce the time and cost of research and design, and it's conducive to the further improvement design for the finished product.

\section{REFERENCES}

[1] Tsai K. \& Tang B. 2014. Determination of injection molding process window based on form accuracy of lens using response surface methodology. International Journal of Advanced Manufacturing Technology, 75(5-8): 947-958.

[2] Weidong Y. 2013. Injection mould for automobile instrument panel. Die \& Mould Industry. 


\section{MATEC Web of Conferences}

[3] Meng-kai B, Qiang N. \& Xiong-hui Z, et al. 2015. Analysis and evaluation method of injection mould cooling system based on CAD/CAE integration. Die \& Mould Industry.

[4] Tsai K. \& Lan J. 2015. Correlation between runner pressure and cavity pressure within injection mold. International Journal of Advanced Manufacturing Technology.

[5] M. Chan W, Yan L. \& Xiang W, et al. 2003. A 3D CAD knowledge-based assisted injection mould design system. International Journal of Advanced Manufacturing Technology, 22(5-6): 387-395.

[6] Lijuan S, Dong-shi X. \& Zhuan H, et al. 2010. Application of Moldflow in design of injection mould. Die \& Mould Industry.

[7] Yongjun X. 2010. Design of Injection Mould for Complicated Knob. Plastics Science \& Technology.

[8] Xizhang L. 2011. Design of injection mould for battery case. Die \& Mould Industry. 